\title{
Editorial \\ SAPHO syndrome: Is a range of pathogen-associated rheumatic diseases extended?
}

\author{
Alexander P Rozin
}

B. Shine Department of Rheumatology, Rambam Health Care Campus and Rappaport Faculty of Medicine, Technion, P.O. Box 9602, Haifa, Bat-Galim, 31096, Israel

Corresponding author: Alexander P Rozin, a_rozin@rambam.health.gov.il

Published: 5 November 2009

Arthritis Research \& Therapy 2009, 11:131 (doi:10.1186/ar2837)

This article is online at http://arthritis-research.com/content/11/6/131

(c) 2009 BioMed Central Ltd

See related research by Assmann et al., http://arthritis-research.com/content/11/5/R140

\begin{abstract}
SAPHO syndrome, representing a constellation of synovitis, acne, palmo-plantar pustulosis, hyperostosis, and osteitis, is now recognized as a distinct medical entity: a reactive infectious osteitis. Genetic, immunological, and bacterial mechanisms are implicated in the development of the disease. Diagnostic problems may arise due to non-complete manifestations of SAPHO: either acne and arthritis or acne and anterior wall osteitis with an unclear pustulosis history. The interventional study of Assmann et al. is a significant addition to a long range of publications showing an association of SAPHO with Propionibacterium acnes. Randomized control studies are needed to confirm the effects of antibiotic therapy.
\end{abstract}

In the previous issue of Arthritis Research \& Therapy, an interventional study of patients with SAPHO (synovitis, acne, pustulosis, hyperostosis, osteitis) syndrome, a skin-osteoarticular inflammatory disease, showed positive bacteriological cultures for Propionibacterium acnes in 14 of 21 $(67 \%)$ patients who had undergone a needle biopsy of osteitis lesions [1]. This is a significant addition to a long range of publications showing an association of SAPHO with $P$. acnes in $42 \%$ of patients (Table 1). The activity of SAPHO, by assessment of skin disease, health assessment score, radiological activity score, and osteitis lesions by magnetic resonance imaging, decreased significantly after 16 weeks of antibiotic therapy. The indices demonstrating disease activity increased after discontinuation of the antibiotic treatment.

The relationship between infection and autoimmunity has been increasingly defined over the last 20 years. In genetically susceptible individuals, environmental factors (mainly infections) play a critical role in the pathogenesis of autoimmune diseases. It is believed that infections contribute to the maturation of the immune system from innate to adoptive phases and that bacterial and viral infections are arthritogenic stimulants leading to various rheumatic conditions. Infectious agents may be the initial trigger of the production of cross-reacting antibodies (molecular mimicry) and may also induce the inflammatory 'second hit' mediated by Toll-like receptors (TLRs) [2]. Molecular similarity of microbial and host antigens (molecular mimicry) has recently been proposed as a promoting factor for pathogen expansion when microbial agents are not recognized as alien and not completely eliminated [3].

Infectious agents isolated from SAPHO patients have merited special attention for many years. Their possible etiological role is supported by the pathogen isolation from different sites: anterior chest wall, spine, synovial fluid, bone tissue, and skin pustules. A range of pathogens have been found, including Staphylococcus aureus, Hemophilus parainfluenzae, actinomyces, and even Treponema pallidum [4]. P. acnes is a much more frequent pathogen and plays a particular role. Of note, speculation about contamination of bone biopsy samples from skin seems to be inconsistent after standard antiseptic procedures in the operation field. $P$. acnes is a Gram-positive, motionless, non-spore-forming bacillus with maximum growth in anaerobiosis. The microorganisms involved in human disease have five biotypes, of which biotypes I and III are the most frequently involved in the etiopathogenesis of acne. They form part of the normal flora of the oral cavity, large intestine, conjunctiva, external ear conduit, and the skin, particularly the sebaceous follicles. In 1987, Trimble and colleagues [5] observed that intra-articular injection of inactivated $P$. acnes in laboratory animals can cause joint lesions and bone erosions.

A genetic background of $P$. acnes seems to be especially relevant since its complete genome sequence has been

$\mathrm{IL}=$ interleukin; $\mathrm{SAPHO}=$ synovitis, acne, pustulosis, hyperostosis, osteitis; TLR = Toll-like receptor; TNF $=$ tumor necrosis factor. 
Table 1

\begin{tabular}{lcc}
$\begin{array}{l}\text { Positive findings of Propionibacterium acnes in bone lesions } \\
\text { in cases of SAPHO syndrome }\end{array}$ & $\begin{array}{c}\text { Propionibacterium } \\
\text { acnes-positive }\end{array}$ \\
\hline Authors & Investigated & 1 \\
\hline Sherusan et al. [16] 1982 & 1 & 1 \\
Collert and Isacson [17] 1982 & 1 & 1 \\
King et al. [18] 1987 & 7 & 7 \\
Edlund et al. [19] 1988 & 15 & 1 \\
Gerster et al. [20] 1990 & 1 & 1 \\
Kotilainen et al. [21] 1996 & 1 & 2 \\
Reith et al. [22] 1996 & 8 & 1 \\
Hayem [10] 1999 & 15 & 8 \\
Kirchhoff et al. [23] 2003 & 14 & 1 \\
Colina et al. [14] 2007 & 6 & 14 \\
Assmann et al. [1] 2009 & 21 & 38 (42\%) \\
Total & 90 &
\end{tabular}

SAPHO, synovitis, acne, pustulosis, hyperostosis, osteitis.

detected and it clearly reveals numerous gene products involved in the degradation of host molecules. This justifies the ability of the germ to colonize and survive in human skin, bone, and synovial fluid [6].

A genetic background in patients may be relevant given that familial clustering has been reported [7]. A murine model characterized by a spontaneous chronic recurrent multifocal osteomyelitis related to a missense mutation of the gene for proline-serine-threonine phosphatase interacting protein 2 (PSTPIP2) located on chromosome 18 also exists [8]. Some similarities with two inherited genetic diseases, Majeed syndrome and PAPA (pyogenic arthritis, pyoderma gangrenosum, and acne) syndrome, further support a genetic background [9]. There is growing evidence that an exaggerated response to intestinal bacteria mediated by the NOD2/ CARD15 (nucleotide-binding oligomerization domain protein 2/ caspase recruitment domain 15) system in the inflammasome (associated with Crohn disease) leading to a nuclear factorkappa-B overactivation may be involved in SAPHO syndrome [10].

Multiple affected members who segregated a SAPHO syndrome-like phenotype had neutrophil dysfunction and reduced internal oxydant production [11]. That may explain the inability of the innate system to eliminate the pathogen from affected sites. This justifies long-term or permanent antibiotic therapy.

It has been demonstrated that $P$. acnes may trigger a nonspecific activation of the complement system and cell- mediated immunity in order to eliminate the germ-inducing perpetuation of the inflammation. The ability of the germ to persist in bone lesions in a form incompatible with culturing is a possible explanation for its difficult isolation. The strong humoral and cellular pro-inflammatory response has recently been reported due to $P$. acnes with elevated interleukin (IL)-1, IL-8, and IL-18 plasma levels and increased IL-8 and tumor necrosis factor-alpha (TNF- $\alpha$ ) production by purified polymorphonuclear cells [12]. $P$. acnes products have chemoattractant properties, and their immunomodulatory activity is mediated by TLR9 [13].

This justifies long-term or permanent anti-inflammatory therapy. SAPHO syndrome is commonly refractory to nonsteroidal anti-inflammatory drugs, glucocorticoids, and diseasemodifying anti-rheumatic drugs. Intravenous biphosphonate pamidronate with its strong anti-inflammatory and lymphopenic effect proved to be effective in achieving long-term remission of SAPHO syndrome [14].

At least six uncontrolled studies showed efficacy of antibiotic therapy (azithromycin, doxycycline, sulfamethoxazole/trimetoprim) in SAPHO syndrome. Long-term antibiotic therapy is recommended in most cases. Some patients may respond to repeated 6-week to 3-month courses with 1- to 2-month intervals in order to prevent resistance to antibiotics.

Anti-TNF- $\alpha$ therapy proved to be effective against osteoarticular manifestations of SAPHO syndrome, but deterioration of skin pustulosis was observed in some patients [15]. Combined therapy, including anti-TNF medication and an antibiotic, may be a reasonable solution.

SAPHO syndrome, representing a constellation of synovitis, acne, palmo-plantar pustulosis, hyperostosis, and osteitis, is now recognized as a distinct medical entity: a reactive infectious osteitis. Genetic, immunological, and bacterial mechanisms are implicated in the development of the disease. Diagnostic problems may arise due to incomplete manifestations of SAPHO: either acne and arthritis or acne and anterior wall osteitis with an unclear pustulosis history. The physician needs to make a careful inquiry about a past history of pustulosis. An early bone scanogram is strongly advised in patients with anterior chest pain and a suspicion of SAPHO syndrome. Due to the remitting course, decreased disease activity might be related to the natural course of the disease and not to the efficacy of the antibiotic therapy. Thus, randomized placebo control studies are needed to document the effects of antibiotic therapy. Further trials are needed to create a model of SAPHO disease using $P$. acnes transfer to healthy animals. Mechanisms of ineffective host responses for neutralizing and eliminating $P$. acnes should also be investigated.

\section{Competing interests}

The author declares that they have no competing interests. 


\section{References}

1. Assmann G, Kueck O, Kirchhoff T, Rosenthal H, Voswinkel J, Pfreundschuh M, Zeidler H, Wagner AD: Efficacy of antibiotic therapy for SAPHO syndrome is lost after its discontinuation: interventional study. Arthritis Res Ther 2009, 11:R140.

2. Amital H, Govoni M, Maya R, Meroni PL, Ori B, Shoenfeld $Y$, Tincani A, Trotta F, Sarzi-Puttini P, Atzeni F: Role of infectious agents in systemic rheumatic diseases. Clin Exp Rheumatol 2008, 26 (1 Suppl 48):S27-32.

3. Rozin AP: From molecular mimicry to cross-reactivity or pathogen expansion? A hypothesis. Clin Rheumatol 2007, 26: 285-288.

4. Arnson $Y$, Rubibow A, Amital H: Secondary syphilis presenting as SAPHO syndrome features. Clin Exp Rheumatol 2008, 26: 1119-1121.

5. Trimble BS, Evers CJ, Ballaron SA, Young JM: Intraarticular injection of Propionibacterium acnes causes an erosive arthritis in rats. Agents Actions 1987, 21:281-283.

6. Brüggemann $H$, Henne $A$, Hoster $F$, Liesegang $H$, Wiezer $A$, Strittmatter A, Hujer S, Dürre P, Gottschalk G: The complete genome sequence of Propionibacterium acnes, a commensal of human skin. Science 2004, 305:671-673.

7. Gonzalez T, Gantes M, Bustabad S, Diaz-Flores L: Acne fulminans associated with arthritis in monozigotic twins. J Rheumatol 1985, 12:389-391.

8. Ferguson PJ, Bing X, Vasef MA, Ochoa LA, Mahqoub A, Waldschmidt TJ, Tygrett LT, Schlueter AJ, El-Shanti H: A missense mutation in pstpip2 is associated with murine autoinflammatory disorder chronic multifocal osteomyelitis. Bone 2006, 38: 41-47.

9. Ferguson PJ, Chen S, Tayeh MK, Ochoa L, Leal SM, Pelet A, Munnich A, Lyonnet S, Majeed HA, El-Shanti H: Homozygous mutations in LPIN2 are responsible for the syndrome of chronic recurrent multifocal osteomyelitis and congenital dys erythropoetic anaemia (Majeed syndrome). J Med Gent 2005, 42:551-557.

10. Hayem G: Valuable lessons from SAPHO syndrome. Joint Bone Spine 2007, 74:123-126.

11. Ferguson PJ, Lokuta MA, El-Shanti HI, Muhle L, Bing X, Huttenlocher A: Neutrophil dysfunction in a family with a SAPHO syndrome-like phenotype. Arthritis Rheum 2008, 58:32643269.

12. Hurtado-Nedelec M, Cholett-Martin S, Nicaise-Roland P, Grootenboer-Mignot S, Ruimy R, Meyer O, Hayem G: Characterization of the immune response in the synovitis, acne, pustulosis, hyperostosis, osteitis (SAPHO) syndrome. Rheumatology (Oxford) 2008, 47:1160-1167.

13. Kalis C, Gumenscheimer M, Freudenberg N, Tchaptchet S, Fejer G, Heit A, Akira S, Galanos C, Freudenberg MA: Requirement of TLR9 in the immunomodulatory activity of Propionibacterium acnes. J Immuno/ 2005, 174:4295-4300.

14. Colina M, La Corte R, Trotta F: Sustained remission of SAPHO syndrome with pamidronate: a follow-up of fourteen cases and review of the literature. Clin Exp Rheumatol 2009, 27:112-115.

15. Massara A, Cavazzini PL, Trotta F: In SAPHO syndrome antiTNF-alpha therapy may induce persistent amelioration of osteoarticular complaints, but may exacerbate cutaneous manifestations. Rheumatology (Oxford) 2006, 45:730-733.

16. Sherusan M, Spencer DL, Yeh WS, Kaminski M, Skosey JL: Osteomyelitis of cervical spine due to Propionibacterium acnes. Arthritis Rheum 1982, 25:346-348.

17. Collert $\mathrm{S}$, Isacson J: Chronic sclerosing osteomyelitis (Garre). Clin Orthop Relat Res 1982, 164:136-140.

18. King SM, Laxer RM, Manson D, Gold R: Chronic recurrent multifocal osteomuelitis: a non-infectious inflammatory process. Pediatr Infect Dis J 1987, 6:907-911.

19. Edlund E, Johnsson U, Lidgren L, Pettersson H, Sturfelt G, Svensson $\mathrm{B}$, Theander J, Willen H: Palmo-plantar pustulosis and sternocostoclavicular arthro-osteitis. Ann Rheum Dis 1988, 47: 809-815.

20. Gerster JC, Lagier J, Livio JJ: Propionibacterium acnes in spondylitis with palmoplantar pustulosis. Ann Rheum Dis 1990, 49:337-338.

21. Kotilainen P, Merilahti-Palo R, Lehtonen OP, Manner I, Helander I, Mottonen T, Rintala E: Propionibacterium acnes isolated from sternal osteitis in a patient with SAPHO syndrome. J Rheumatol 1996, 23:1302-1304.
22. Reith JD, Bauer TW, Schils JP: Osseous manifestations of SAPHO (synovitis, acne, pustulosis, hyperostosis, osteitis) syndrome. Am J Surg Pathol 1996, 20:1368-1376.

23. Kirchhoff $T$, Merkesdal S, Rosenthal H, Prokop M, Chavan A, Wagner A, Mai U, Hammer M, Zeidler H, Galanski M: Diagnostic management of patients with SAPHO syndrome: use of MR imaging to guide bone biopsy at CT for microbiological and histological work-up. Eur Radio/ 2003, 13:2304-2308. 